\title{
VIRTUAL PAST. INTERACTIVE PRESENTATION OF LATE ROMAN TOWERS (ARCHAEOLOGICAL MUSEUM, MILAN ITALY).
}

\author{
S. Morandi ${ }^{1}$, M. Tremari ${ }^{2}$ \\ ${ }^{1}$ Independent researcher, freelancer - simomorandi@yahoo.com \\ ${ }^{2}$ SAP Società Archeologica s.r.l., Albavilla (CO), Italy - marcotremari@ gmail.com
}

KEY WORDS: archaeological heritage; photogrammetry; 3D modeling; Augmented and Virtual Reality; 3D mapping of stratigraphy; late roman site; comunication of $\mathrm{CH}$

\begin{abstract}
:
The work is an analysis of the recording, processing and presentation of the 3D data of two late roman towers inside the area of the Archaeological Museum of Milan, part of the city previously occupied by the Monastery of St. Maurizio and rich of historical and ancient monuments. The aim of this research is to examine the possibilities offered by digital technologies to record and enhance the archaeological heritage and to increase the divulgence and presentation with interactive products.
\end{abstract}
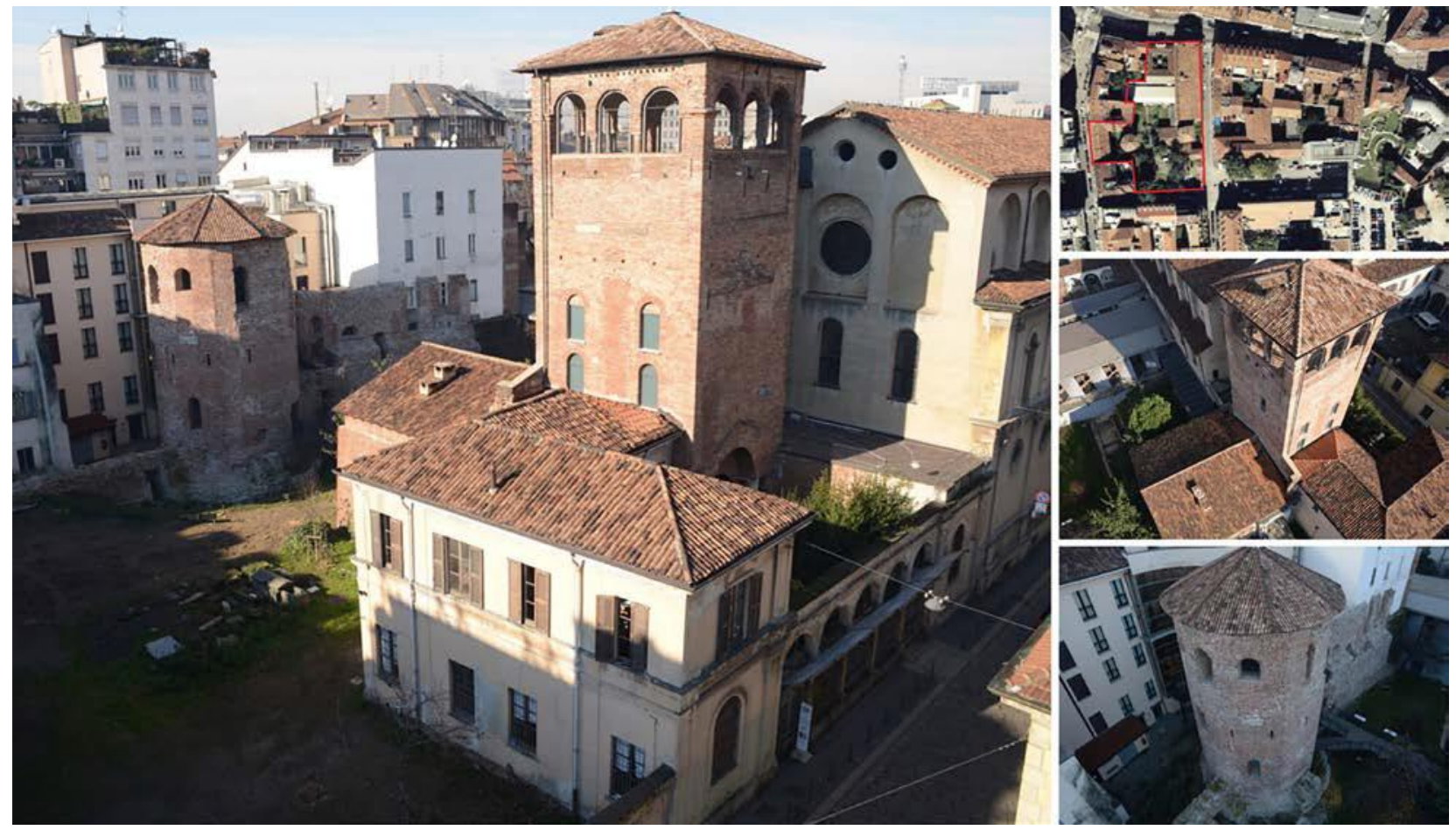

Figure 1. The site of the Archaeological Museum of Milan previously occupied by the Monastery of St. Maurizio: a panoramic view of the area (left) and aerial views of the site and towers (right).

\section{INTRODUCTION}

The aim of this paper is to show the use and the potential offered by modern digital 3D modeling technologies, mostly the digital photogrammetry and the virtual archaeology, to record and enhancing the archaeological heritage and to increase its presentation and divulgence with interactive products.

The research presented here is an analysis of the recording, processing and presentation of the $3 \mathrm{D}$ data of a late roman towers inside the area of the Archaeological Museum of Milan, part of the city previously occupied by the Monastery of
St.Maurizio and rich of historical and ancient monuments (fig.1).

The survey and three-dimensional documentation of the towers was realized during the project sponsored by the City of Milan for the restoration work and valorization of the monumental complex "Polygonal tower, Roman walls and circus tower" built in the late Roman period as part of the magnificent plan of Maximian (286-305 AD) when Milan was capital of the Western Roman Empire.

The primary objective of this application was to preserve digitally the historical site and roman tower in 3D with high 
fidelity and precision, and to provide a 3D multimedia experience for research and educational purposes.

The union of the 3D model managed by Augmented Reality (AR) e Virtual Reality (VR) technologies with mobile devices gives several opportunities in the field of study and communication, improving on-site exploration of the landscape and the monuments, enhancing the archaeological sites.

\section{THE SITE}

The Archaeological Museum in Milan, inaugurated in 1965, is in an area rich in historical significance and ancient monuments: the area of the Monastery of St. Maurizio. In its cloister in fact there are two exceptional towers attributable to the period in which Mediolanum became the imperial seat (late 3 rd - 4th century).

These structures, now symbol of the museum, are a square tower that closed the short side of the Roman circus and a polygonal tower attached to a huge tract of the city walls, structures that survived the subsequent destruction because embedded in the medieval monastery, first as a bell tower of the monastery church, the other as a place of prayer. In the garden, between the two towers, there are also located the remains of a domus built in the late first century B.C. and already it demolished during the urban renewal of the late $3^{\text {rd }}$ century A.D. This area of the Roman city, in the corner formed by the city walls, was occupied by the Roman Circus and its square tower, and the connecting wall to one of the surviving towers on the city wall circuit. The area enclosed by these structures was probably the home to a small garrison. The area later fell into decay and was taken over, in the early medieval period, for the construction of the monastery, the remains of which are still visible today in the grounds of the Museum(fig.2)

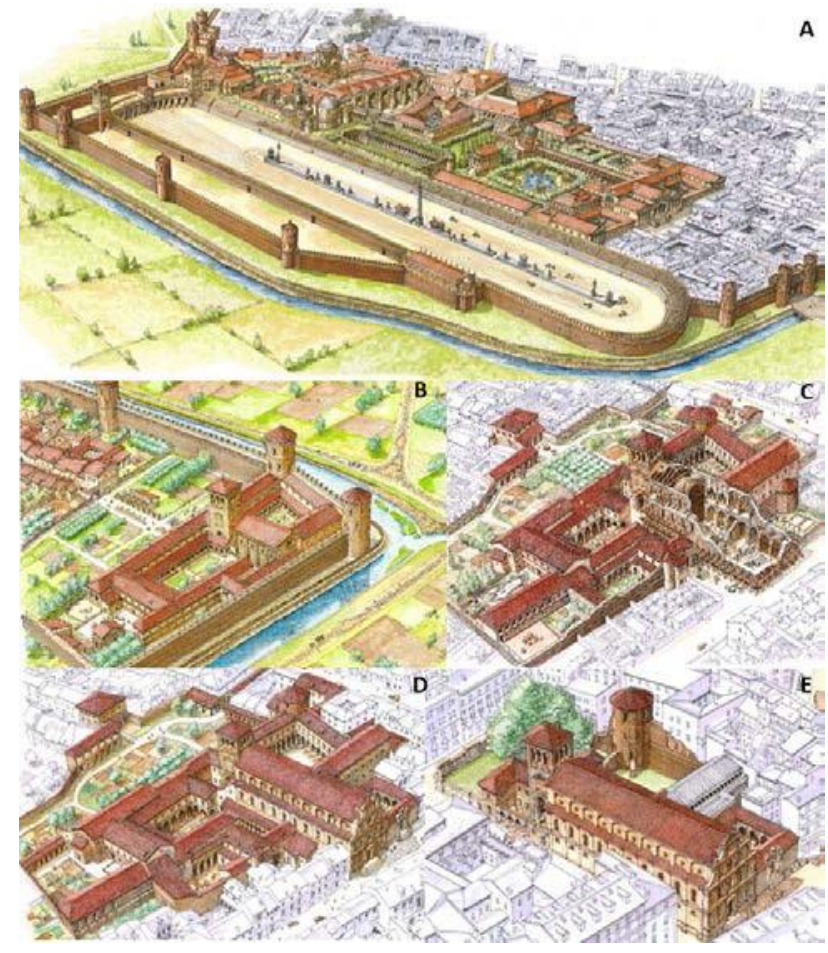

Figure 2. The Area of the Circusr (by F.Corni): A- Roman $3^{\text {rd }}-$ $4^{\text {th }}$ century; B- Monastery $8^{\text {th }}-9^{\text {th }} ;$ C- $16^{\text {th }}$ the Church; D- $17^{\text {th }}$ $18^{\text {th }}$ Transformation; E 20th century Museum's Area.
Between the end of the Longobard period and beginning of the era of Charlemagne ( $8^{\text {th }}-9$ th century A.D.), the Great Benedictine Women's Monastery was constructed on the ruins of the Circus and Imperial Palace, using the city walls as a base. The only surviving part of the Middle Ages monastery is the arched lodge which crowns the square tower of the Roman circus, transformed into a bell tower, between the 8th-9th century and a cycle of frescoes painted in the polygonal tower (dated back to the end of the 13th century - beginning of the 14 th century).

During the $16^{\text {th }}$ century, the Monastery expanded and was transformed; new buildings were erected which required the demolition of preceding structures and large areas of land. The new church, completely re-built on the previous and smaller Middle Age building between 1503-1511, consisted of two halls one for the enclosed order and one for the faithful, separated by a wall, which exactly corresponded to the ancient Roman city wall. With the growth of the Monastery, the towers were progressively surrounded by structures from the medieval period until the dissolution of the monastery, in the $17^{\text {th }}$ century. broken up after the Napoleonic suppression in 1798, the monastery gradually lost its original structure and became, successively, a barracks, school, prison, police and military station (Blockley, 2012)(fig.2)..

During the Second World War, the area suffered severe fire during an incendiary raid and immediately after the war the damaged structures were demolished, freeing the circular tower, and allowing for a campaign of restoration carried out in the 1950s and 1960s, till the foundation of the Museum (fig.3)

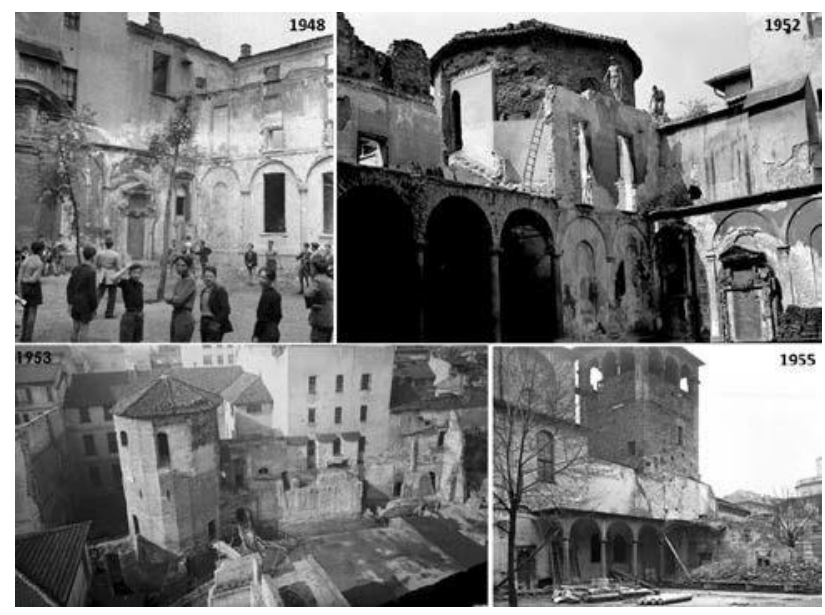

Figure 3. The transformations of cloister of the Monastery of St. Maurizio in the years following the Second World War.

\section{THE SURVEY AND THE METHODOLOGY}

The work revolved around the necessity for a group, composed entirely of archaeologists, to find immediate and economical solutions to apply during the survey, the study and the communication of the archaeological sequence of the prospects of the two late Roman towers.

The primary objective of this application was to preserve digitally the historical site and roman tower in 3D with high fidelity and precision, and to provide a 3MD multimedia experience for research and educational purposes.

During fieldwork, the methodology and software employed were very sustainable, intended at surveying the site and 
considering the issues related to the disclosure of the acquired and processed archaeological data, for the audience of visitors, not only for scholars and for professionals.

In the course of the restoration work, the plaster was removed from the interior of the square towers and it was possible to complete the documentation of these complex structures, Given the height of the towers preserved up to 23 meters, and the problems involved in conducting a traditional photogrammetric survey in barely accessible areas, it was decided to carry out the acquisition of data by the technique of uncalibrated photogrammetry, 3D image-based modelling. This permitted the construction of a $3 \mathrm{D}$ model of all the structures, in the area under study.

The first step of the work was the realization of a photographic coverage of the site, aimed at creating a detailed mapping and georeferenced contextualization of the roman structures and the generation of a 3D model thought the use of the modern digital photogrammetry.

The towers, still well preserved in the area of the Museum (the polygonal tower up to 17 meters high, and the square tower up to 23 meters) were subject to survey using 3D modeling and non-calibrated photogrammetry, applying the techniques of close range and aerial photogrammetry, now well consolidated during the last few years in the realm of architectural and engineering survey.

This methodology was applied because the traditional methodology of topographic survey and photogrammetry did not give satisfactory results, especially in the less accessible areas due to the presence of structures (such as the stairwell constructed in the square tower in the $20^{\text {th }}$ century) and the height of the elevations (Morandi, 2017).

The image-based 3D modelling is important tool for producing realistic and accurate 3D models in a practical and costeffective manner. This method of three-dimensional recording, through uncalibrated photogrammetry, makes use exclusively of digital photographs to produce a 3D reconstruction of real objects, based on the integration of data acquisition, modelling and representation and is a suitable technique for areas such as archaeological recording reducing drastically with this methodology time and effort required during the survey (Taylor et al., 1996; Manfredini et al.2010).

The application of 3D image-based modelling method on this archaeological site, using a simple acquisition hardware (digital camera) and low cost software for data processing, has led to a notable increase in the quality and amount of documentation; moreover, it has also reduced drastically the time and effort during on-site acquisition, processing and visualisation.

Photogrammetry allows the conversion of the photographed environment into a measurable three-dimensional model, with much more details and information than it is possible to obtain with traditional topographic survey and data accuracy is comparable to that of the $3 \mathrm{D}$ representations obtained from laser scanner (Fassi et al., 2011).

The acquisitions on site were made both with aerial and terrestrial photogrammetry (fig.4). The first step was the acquisition of orthogonal and oblique images for the contextualization of the archaeological structures within the museum complex, using close range aerial.

To this end, we made use of a small tethered helium-filled zeppelin, suitable for rapidity, accuracy and cost-effectiveness and easier to use for causes of accessibility in urban zones than drones.
The zeppelin carried a 24 megapixel full frame Nikon D600 mounted on a radio-controlled pantograph with remote shutter release. This method permitted the access to the square tower, overcoming the problems represented by the presence of buildings huddled to its base (fig.5).

The second stage was the photographic recording of the internal prospects of the polygonal tower ( 24 sides) and square tower, taking advantage of a custom-built structure consisting of a telescopic mast mounted on a tripod base, which could reach the height of 8 meters.

The mast carried a Panasonic DMC-GH4 16 megapixel camera with remote control settings, permitting shooting and verification on a screen, using a simple smartphone.

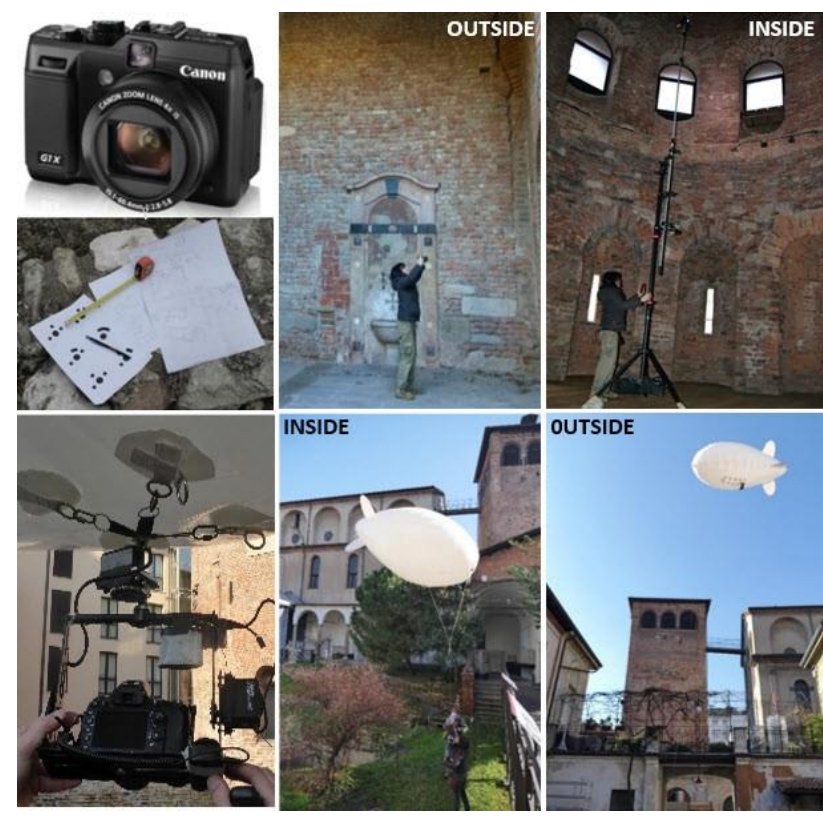

Figure 4 Aerial and terrestrial photogrammetry

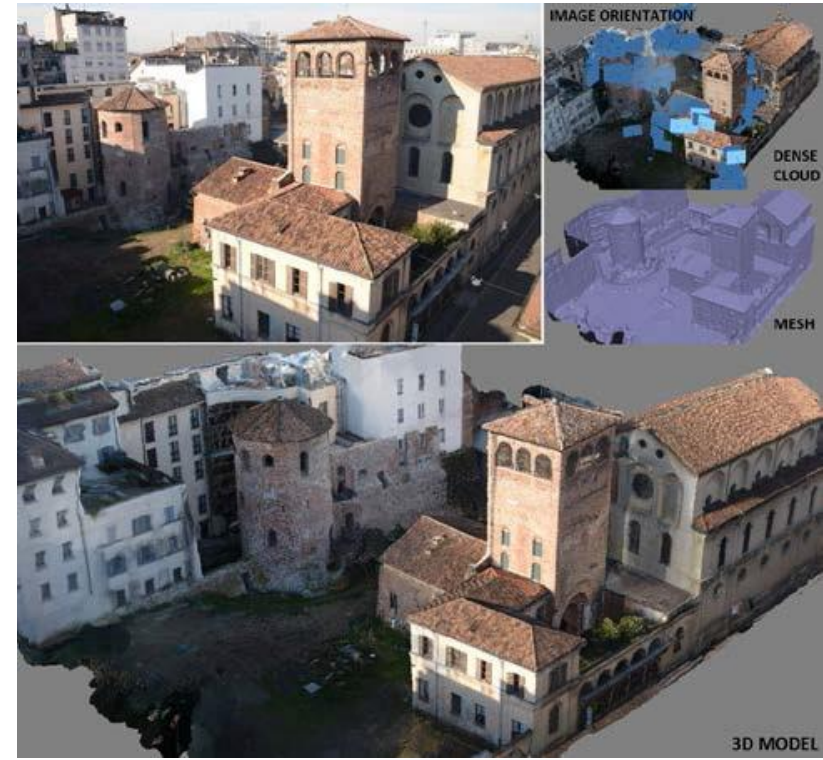

Figure 5 The site and the 3D model

The low-cost software, Agisoft PhotoScan, was used to process the data obtained digital close range photogrammetry and aerial photography. This software automatically orientates even very large set of images and generates high-density point cloud from 
which graphics processing is then applied to extract a 3D photorealistic model, a scaled and detailed texturized representations of the archaeological data, and 2D plans and prospects (fig.6).
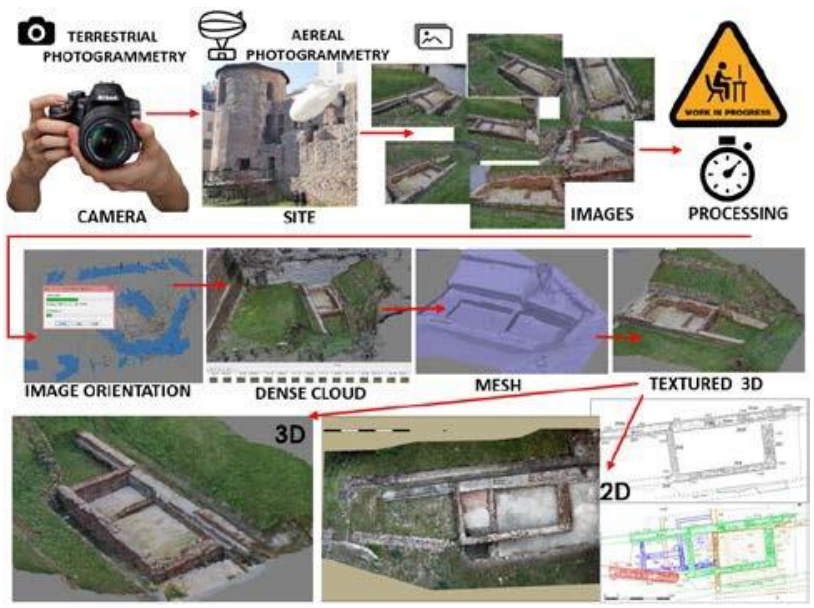

Figure 6 Workflow: from the photos obtained with digital photogrammetry to 3D models and 2D plans.

The aim of this work was to survey and process the digital data to obtain an accurate three-dimensional model, which has the benefit of instantly displaying the object in its entirety: an authentic photorealistic reproduction from which the data could be then extracted for the two-dimensional analysis of the structural details and transformations (fig.7, fig.8).

The 3D model of the archaeological evidence is extremely important not only for study, allowing the archaeologist to develop and display the data thanks to continuous contact with the object of research within the three-dimensional space, but also for aspects of the conservation and monitoring of the monument.

The 3D model has in fact various and efficacious values as scientific, didactic, historical and additional depending on the information that it provides, and it can also be suitable to estimate the evolution of the environment quantifying the changes in the area through time.

This virtual copy has also the advantage of instantly representing the object in its original architecture and entirety, making available the data to a general public, of not only scholars and professional and helping people to visualize the ancient site and comprehend it better (Russo et al, 2011).

The photographic documentation with digital photogrammetry, made the generation of detailed ortophotos relatively simple for even the difficult not accessible areas.

The ortophotos extracted from the 3D model, representing the $2 \mathrm{D}$ prospects, were imported into AutoCAD to form the underlying image for the analysis of the stratigraphic sequence of the towers and the vectorization of the structures; the phases studied were indicated with different hatches and colors for each phase and sub- phase on the ortophotos .

The same stratigraphic phases, corresponding to the transformation of the structure over the centuries, have been also indicated directly on the 3D model obtained by photogrammetry, so that they could be perceived threedimensionally, using Zbrush software.

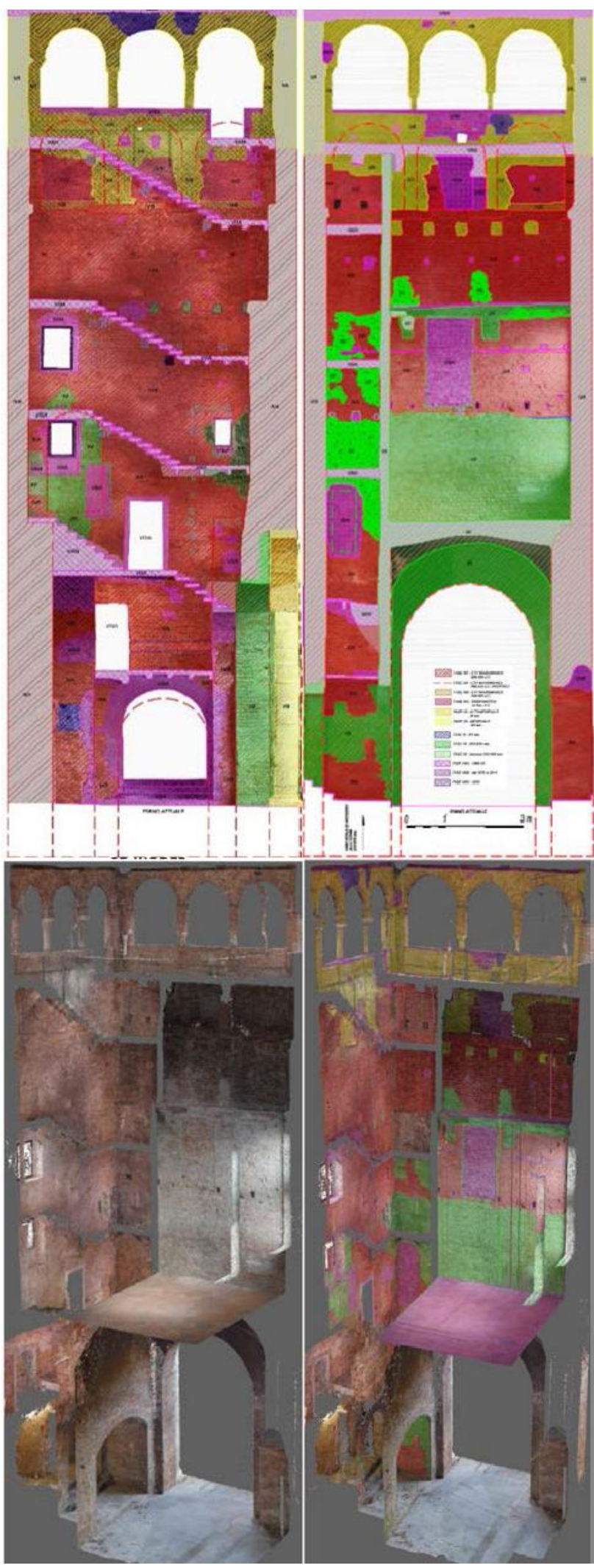

Figure 7. Square tower: internal prospects with indication of the phases on the orthophotos (above) and the stratigraphic phases projected on the 3D model (below)

The historical evolution of the tower, mapped on the model, make possible to rebuild 3D representations of it in the different periods. 

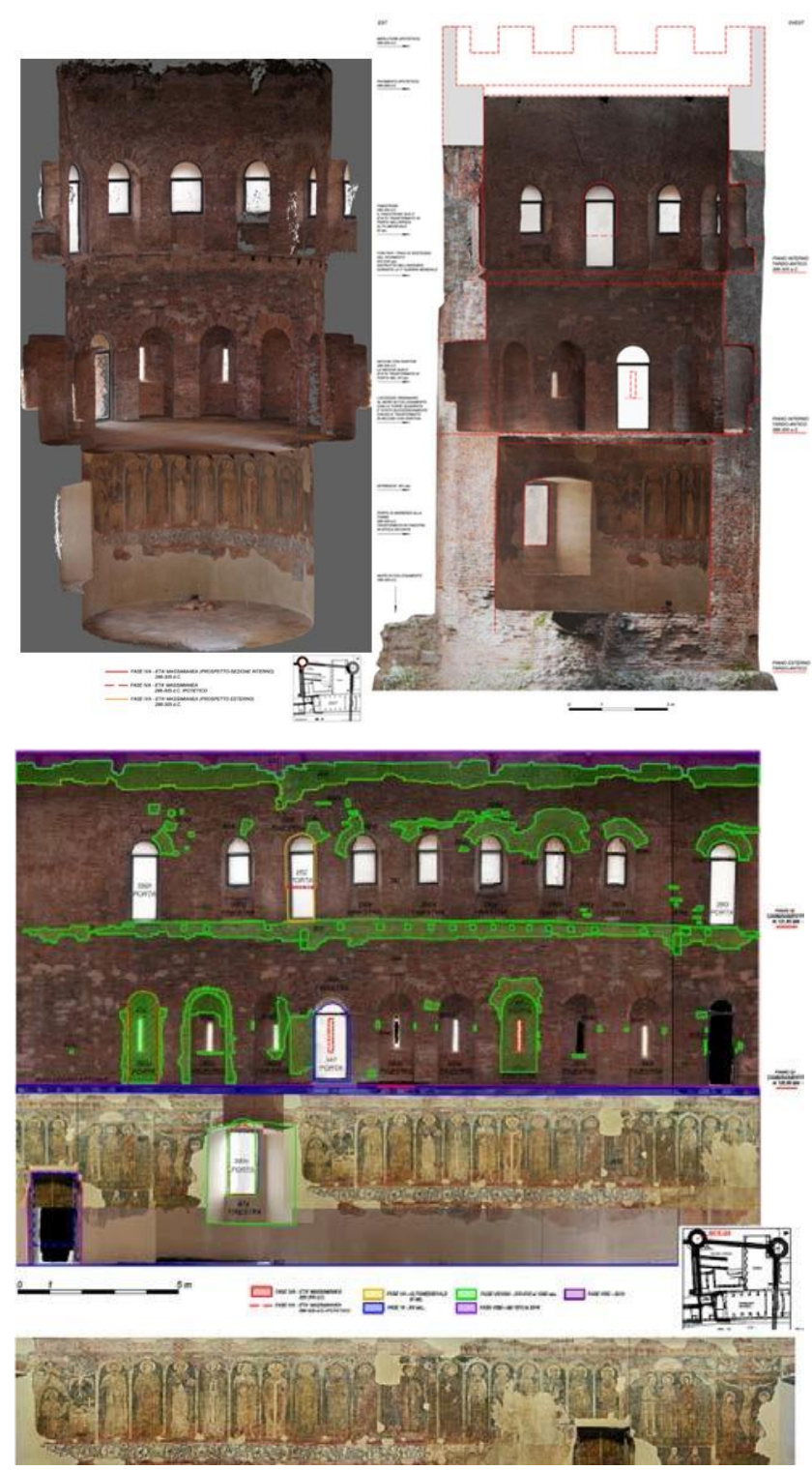

Figure 8. 3D model from digital photogrammetry: the polygonal tower sectioned E-W and prospects with interpretation

\section{RESULTS AND FUTURE APPLICATION}

The 3D models of towers proved to be an effective tool for the dissemination of archaeological data and were the starting point for different communication solutions that allows visitors to take a virtual tour of the same through applications for smartphone and tablet.

The availability of the 3D models, produced by photogrammetric survey (IBM), allows the application of AR and VR, technologies that contribute to a greater involvement in the knowledge of archeological remains thanks to personalized browsing of real and digital scenes.

This will be of great value, for example to visitors who are unable to climb the stairs to explore the towers in person: they will be able to navigate and interrogate them from a video screen. AR and VR allowing to recognize the different phases of the tower on the 3D model, will be also useful for archeologist and students.
After the archaeological survey, the need for a non-traditional and alternative method of musealization of the site context was immediately clear.

As the structures were no easy visible, without enter the museum, we decided to use the AR solution as a way to explore and enjoy the late roman towers, giving people the possibility of a virtual visit of them.ar has been used for the 3D rendering of the entire archaeological area.

One custom marker was created, suited to be recognized by the software responsible for reproduction in AR environment of the photorealistic 3D model (Milgram et al., 1994).

This marker for AR applications will be included in the brochure made by the Archaelogical Museum to enrich it with the three-dimensional model and multimedia contents available for tourism and divulgation.

The user could also interact with panels that will be located outside the museum.

This will be of great value for visitors that will be able to navigate the interior area of the museum with the two towers from a video screen (fig.9).

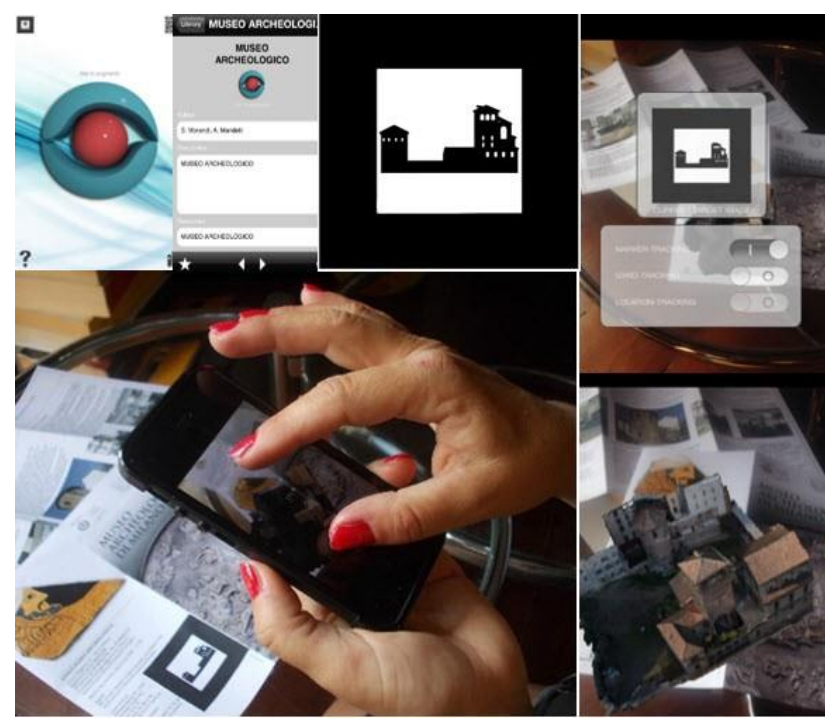

Figure 9 . The 3D model of the site and towers managed by AR: the brochure with the AR marker and the view site 3D model

Furthermore, the panoramic camera Ricoh Theta was used to capture $360^{\circ}$ images of the Museum's area and the interior of the towers; the panoramic photos were stitched together with the proprietary software and a virtual tour of the site and the reconstruction of the church during the times was created with Kolor Pano Tour software (fig10).

The virtual tour is going to be published to use it with a simple virtual reality head mounted display (HDM) and an application for smartphone (Fabola et al. 2016).

This system produces an immersive experience permitting the virtual visit of the archaeological site in order to understand how the landscape and the site have transformed also to people who are unable to visit the site in person.

The direct fruition of the virtual model through a fully immersive VR tour could open the path for an innovative development in the field of archaeology maintenance, improving our understanding of the spaces and allowing to immediately georeference the information (Fassi et al 2016). 


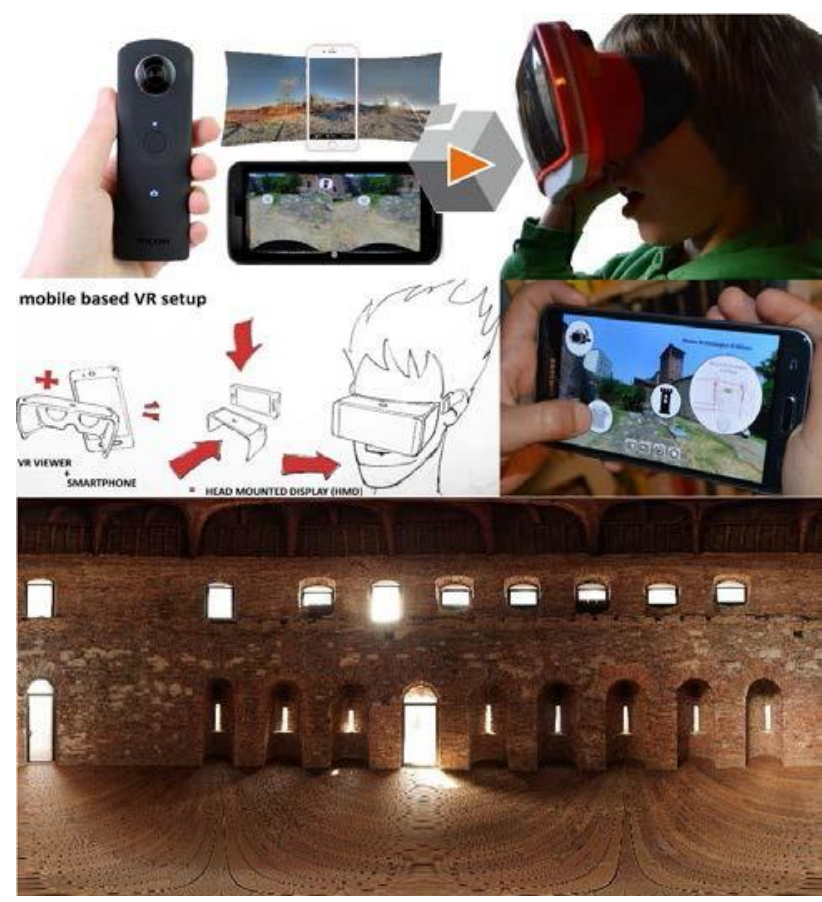

Figure 10 Explanation of the mobile based VR and $360^{\circ}$ panoramic view of the polygonal tower navigable in VR

The purpose was to realize a virtual tour of the area to display the nowadays view of the archeological site, the stratigraphic phases of the structures mapped directly on the 3D model and the $3 \mathrm{D}$ reconstruction of the area in different periods. (fig. 11)

The future intention is to realise a virtual reconstruction of the area in both the late roman and medieval period, so it will be possible to have some panoramic views of the area as it was in the past. The visitor using AR e VR could perceive the evolution of the tower over the centuries and recognize in the masonry elevation the structures corresponding to each phases of its life.

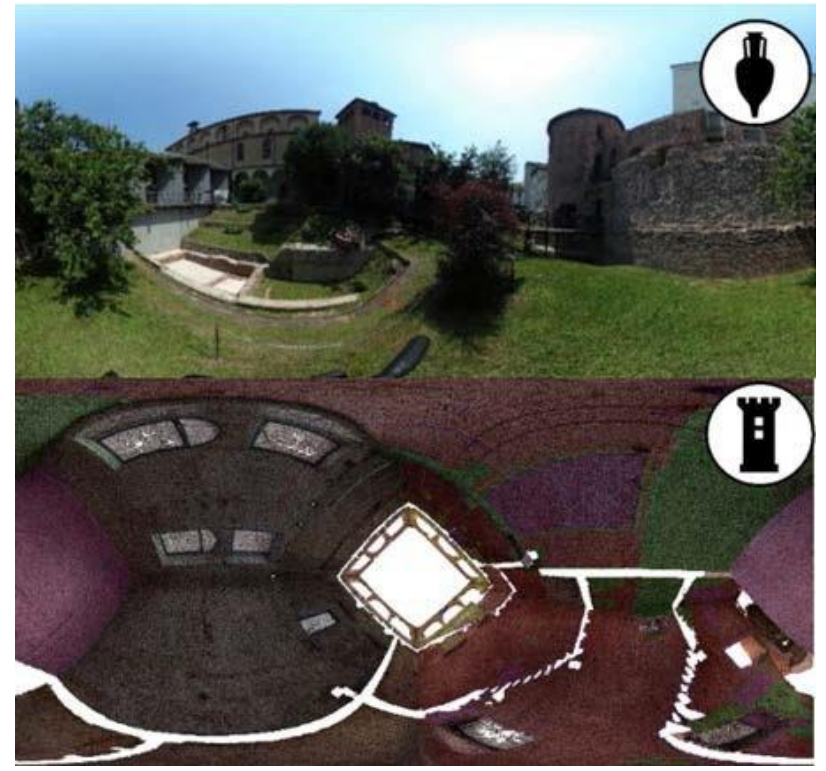

Figure 11 Explanation of the mobile based VR and $360^{\circ}$ panoramic views of the area and the stratigraphy tower navigable in VR
A firm specialized in computer applications for museums (ETT), did in collaboration with the Museum an application to make an interactive presentation of the towers, accessible by smartphone. The application is making use of our 3D survey, $\mathrm{AR}$ and VR to add a new dimension to the presentation of the archaeological remains and make the towers "accessible" by smartphone via beacon from the base 7 .

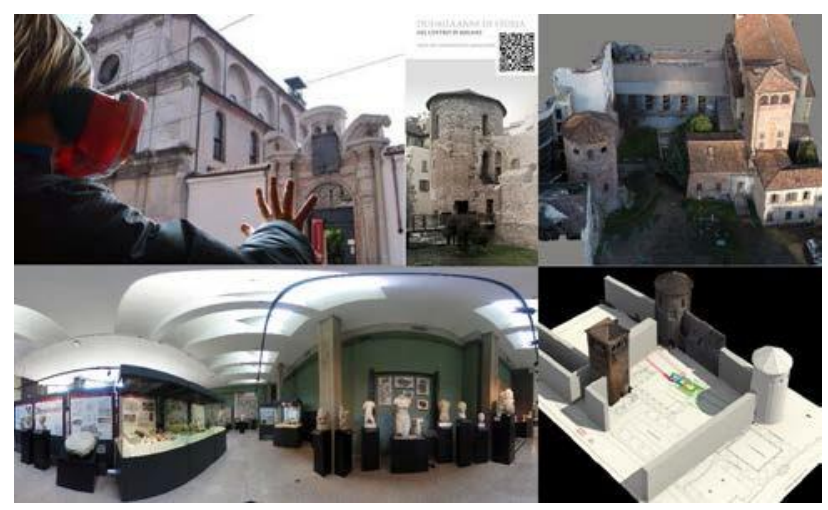

Figure $12 . \mathrm{VR}$ and $360^{\circ}$ panoramic view and ETT application.

The 3D model has been also merged into an interactive digital publication system, represented by 3D PDF, with models that can be explored by the viewer, queried and easily downloaded by the scanning of a QR code from the Museum's website (Fiorini, 2012).

\section{CONCLUSION}

The technological improvements in spatial data collection and 3D imaging developments are changing our perception of the real world; surveying, data processing, modeling, Augmented and Virtual Reality, are main elements of these development processes to achieve the output products.

The application of digital photogrammetry and the virtual reconstruction at the area of the archaeological Museum of Milan was particularly interesting and effective producing a conspicuous increment in the amount and quality of the documentation.

Considering that, at the time of the survey, no documentation of the interiors of the towers was available, after few days of survey and elaboration of data, 2D and 3D graphic documentation of the whole archaeological area was obtained, suitable both for scientific and informative purposes.

The three-dimensional models both reality-based and hypothetic run by $\mathrm{AR}$ and $\mathrm{VR}$ technologies with mobile devices provides several advantages in the research, study and communication, improving on-site exploration of the landscape and the archaeological sites.

The case of study presented would be a model to valorize with low cost and non-invasively technologies the archaeological heritage with interactive products that increase the study, the presentation and the divulgence. Acquired data are the basis of many usable applications.

First, they are an authentic image of the present status of the archaeological structures, at a precise moment of the survey. This information can be useful later to control the natural decay of the remains or possible damage. 
Besides, the data may also be used to prepare a digital reconstruction of the original appearance of the whole the site and landscape, effective both for academic and popular publications.

The interactive products potentially increase the divulgation and visualization for the general public, in the belief that the preservation and protection of the archaeological heritage is possible only through its knowledge and the disclosure to a larger audience.

\section{ACKNOWLEDGEMENTS}

Thanks are due to Dr. D. Caporusso, of the Archaeological Museum of Milan, who oversaw the project and, together with Dr. A. Provenzali, offered advice and help at all times, to $\mathrm{P}$. Blockley (Ra.Ga. S.r.l.) for the archaeological data, to $\mathrm{N}$ Pozzato (Studio R3D) for the photographs with the zeppelin, and D. Botturi (Moovie S.r.l.) who made the telescopic pole system for the indoor recording.

\section{REFERENCES}

Blockley, P., Cecchini, N., Pagani, C., 2012, L'area archeologica del Monastero Maggiore di Milano. Una nuova lettura alla luce delle recenti indagini in Quaderni del civico museo archeologico e del civico gabinetto numismatico di Milano, fasc.4, Ferrara.

Morandi, S., 2017 Le torri romane: documentazione e studio attraverso l'image based 3Dmodelling, Il progetto, la ricerca e la comunicazione del dato, in D. Caporusso, Le Torri Romane del Monastero Maggiore, , Quaderni del civico museo archeologico e del civico gabinetto numismatico di Milano, n.6,pp. $97-107$

Taylor, C.J., Devebec P., Malik, 1996, Recostructing polyhedral models of architectural scenes from photografs." Proceedings of the European Conference on Computer Vision,

Fasi, F., Fregonese,, L., Ackermann, S., De Troia, V., Comparison between laser scanning and automated 3D modelling techniques to reconstruct complex and extensive cultural heritage areas. ISPRS Workshop 3D-ARCH: 3D virtual reconstruction and visualization of complex architectures, Trento, (2013) pp.73-80

Manfredini., M., Remondino, F., 2010, Modellazione 3D da immagini. Pipeline Fotogrammetrica, in "Modelli Digitali 3D In Archeologia: Il Caso Di Pompei, Benedetti, Gaiani., Remondino Pisa, pp. 162-199

Russo, M., Remondino, F., Guidi, G.,2011. Principali tecniche e strumenti per il rilievo tridimensionale in ambito archeologico. Archeologia e Calcolatori, 22, pp.169-198.

Milgram, P., Kishino F., 1994, A taxonomy of mixed reality visual displays in «IEICE »Transactions on Information Systems, Vol E77-D, No.1
Fabola, A, Miller, A., 2016 Exploring the past with google cardboard, in Digital Heritage, pp.277-284

Fassi, F., Mandelli ,A., Teruggi, S., Rechichi,F., Fiorillo, F., Achille, C., 2016, VR for Cultural Heritage. A VR-Web-BIM For The Future Maintenance Of Milan's Cathedral, Salento AVR16

Fiorini,A., 2012, Tablet Pc, fotogrammetria e pdf 3D: strumenti per documentare l'archeologia in «Archeologia e Calcolatori», $n$ 23, pp. 213-22 